\title{
Pathogen- and antibiotic-specific effects of prednisone in community-acquired pneumonia
}

\author{
Sebastian A. Wirz ${ }^{1,7}$, Claudine A. Blum ${ }^{2,3,7}$, Philipp Schuetz ${ }^{3}$, Werner C. Albrich ${ }^{4}$, \\ Christoph Noppen ${ }^{5}$, Beat Mueller ${ }^{6}$, Mirjam Christ-Crain ${ }^{2,7}$ and Philip E. Tarr ${ }^{1,7}$ \\ for the STEP Study Group ${ }^{8}$
}

\begin{abstract}
Affiliations: 'Infectious Diseases Service and University Dept of Medicine, Kantonsspital Baselland, University of Basel, Bruderholz, Switzerland. ${ }^{2}$ Endocrinology, Diabetology and Metabolism, Dept of Internal Medicine and Dept of Clinical Research, University Hospital Basel, Basel, Switzerland. ${ }^{3}$ Medical University Dept, University of Basel, Kantonsspital Aarau, Aarau, Switzerland. ${ }^{4}$ Division of Infectious Diseases and Hospital Epidemiology, Cantonal Hospital St. Gallen, St. Gallen, Switzerland. ${ }^{5}$ Division of Genetics and Molecular Biology, Viollier AG, Basel, Switzerland. 'University Dept of Medicine, Kantonsspital Aarau, University of Basel, Aarau, Switzerland. ${ }^{7}$ These authors contributed equally. ${ }^{8}$ Members of the Steroids in Pneumonia (STEP) Study Group are listed in the acknowledgement section.
\end{abstract}

Correspondence: Philip E. Tarr, Infectious Diseases Service, Kantonsspital Baselland, University of Basel, $\mathrm{CH}-4101$ Bruderholz, Switzerland. E-mail: philip.tarraunibas.ch

ABSTRACT In a double-blind, randomised, placebo-controlled trial of hospitalised patients with community-acquired pneumonia (CAP), we demonstrated shorter time to clinical stability (TTCS) with adjunct corticosteroid therapy compared with placebo.

We did a pre-planned, exploratory analysis of any association between microbiological diagnosis, antibiotic treatment and procalcitonin level and effect of prednisone on TTCS, mortality, and CAP complications ( $n=726$ participants, enrolled between December 2009 and May 2014). Multiplex viral real time PCR was systematically performed in nasopharyngeal swabs beginning November $2011(\mathrm{n}=489)$. Other investigations and treatments were at the discretion of the physician. Effect modification was tested with inclusion of interaction terms in the statistical models.

Reduced TTCS with prednisone was seen in all microbiological, antibiotic, procalcitonin and afebrile patient subgroups. We found evidence for a different prednisone response in patients with pneumococcal pneumonia in whom intravenous antibiotic duration was not shorter (interaction $\mathrm{p}=0.01$ ) with prednisone, as was observed in the remaining study population. In patients without macrolide treatment, rehospitalisations were not lower with prednisone (interaction $\mathrm{p}=0.04$ ). After adjustment for multiple testing, these subgroup effects were no longer significant.

Prednisone was associated with shorter TTCS independent of CAP aetiology. In pneumococcal pneumonia, prednisone effects on secondary endpoints may be less favourable.

@ERSpublications

Prednisone was beneficial in all microbiological, antibiotic, procalcitonin and afebrile patient subgroups http://ow.ly/xeoY302nZPx

Editorial comment in Eur Respir J 2016; 48: 984-986.

This article has supplementary material available from erj.ersjournals.com

Received: March 052016 | Accepted after revision: May 302016 | First published online: July 282016

This study is registered at clinicaltrials.gov with identifier number NCT00973154.

Conflict of interest: Disclosures can be found alongside this article at erj.ersjournals.com

Copyright OERS 2016 


\section{Introduction}

In the largest randomised, double-blind trial of short-term corticosteroid treatment in hospitalised community-acquired pneumonia (CAP) patients performed to date, we recently demonstrated shorter time to clinical stability (TTCS), shorter length of hospital stay, shorter duration of intravenous antibiotics, and a trend towards fewer pneumonia-associated complications with $50 \mathrm{mg}$ prednisone given orally for 7 days versus placebo [1]. A recent meta-analysis [2] confirmed the external validity of our results and strengthened the debate in favour of the use of corticosteroids in CAP [3-7].

It is unknown whether the effect of adjunct corticosteroids might differ depending on microbiological CAP aetiology, as it does, for example, in patients with bacterial meningitis [8]. In one previous CAP trial, the cure rate was lower and late failures were more common in patients with pneumococcal pneumonia treated with adjunct prednisolone compared to placebo [5]. There is also concern that corticosteroids could have a detrimental effect in patients with viral pneumonia, including influenza and coronavirus infections [9-15]. However, most of these studies were observational, suggesting the need for additional research.

We therefore aimed to investigate whether the prednisone effect varies in subgroups of patients according to microbiological diagnosis from our previously published randomised trial of adjunct short-term prednisone treatment in patients hospitalised with CAP [1]. The primary endpoint was TTCS. Secondary endpoints included 30-day mortality and CAP complications. Because in clinical practice a microbiological CAP diagnosis is made in only approximately $30-50 \%$ of hospitalised patients $[5,6,16-18]$, we also analysed whether the corticosteroid effect differs according to antimicrobial CAP treatment or according to initial procalcitonin level, a surrogate marker of bacterial infection [19-21]. Finally, the concern has been expressed that the more rapid TTCS with prednisone might be simply related to an antipyretic effect of corticosteroids [22]. To address this concern, we analysed TTCS separately in patients with and without fever at baseline.

\section{Methods}

\section{Study design and patients}

Methodology and main results of the Steroids in Pneumonia (STEP) Trial have been published recently [1]. Briefly, 785 patients hospitalised with CAP in seven Swiss tertiary care centres between December 1, 2009 and May 21, 2014 were randomised to receive either prednisone (50 mg orally for 7 days) or placebo in a double-blind fashion. Microbiological investigations and antimicrobial treatment were at the discretion of the attending physician. Given the emerging concern regarding potential adverse effects of corticosteroids in patients with influenza A H1N1 infection, multiplex viral real-time PCR (Anyplex II RV16; Seegene, Seoul, South Korea) targeting 17 respiratory viruses in nasopharyngeal swabs was systematically performed in all patients enrolled after November 1, 2011 ( $\mathrm{n}=489$; supplementary methods). The present analyses include 726 trial patients treated per-protocol.

\section{Statistical analysis}

As in the initial study protocol [1], the primary endpoint was TTCS, defined as stabilisation of vital signs at two consecutive measurements $\geqslant 12 \mathrm{~h}$ apart. Secondary outcomes included length of hospital stay, all-cause mortality, re-hospitalisation, secondary intensive care unit (ICU) admission (defined as a patient initially admitted to the regular ward, and transferred to the ICU after study medication was given), duration of total and intravenous antimicrobial therapy and incidence of complications from admission until day 30, including recurrent pneumonia and empyema.

To study the effects of corticosteroids in predefined subgroups as defined below, we calculated regression models and included interaction terms. Significant results in interaction analysis provide evidence for effect modification according to subgroup membership. Therefore, interaction p-values $>0.05$ indicate that the effect of prednisone versus placebo did not differ significantly between the respective subgroup and the remaining study population, while interaction $\mathrm{p} \leqslant 0.05$ suggests a difference. Note that the $\mathrm{p}$-value refers to the interaction and not to the effect within the subgroup. This analysis was done unadjusted first (results shown in supplementary table S1) and later adjusted for important baseline variables to prevent confounding within small subgroups, including age, pneumonia severity index (PSI) class, heart failure, and cerebrovascular disease.

Subgroup analysis was performed for groups containing $\geqslant 10$ patients, which included patients with any pathogen, any bacterial pathogen, pneumococci, influenza and other viral CAP diagnoses. Patients with evidence of mixed (bacterial and viral) infection were assigned to the bacterial category given that the pathogenic role in CAP of viruses recovered from nasopharyngeal swabs was unproven in patients with a concurrent bacterial CAP agent $[23,24]$. Additional subgroups were also defined a priori and were based on the type of administered antimicrobial treatment regimens ( $\beta$-lactam/macrolide combination versus $\beta$-lactam monotherapy versus all other antibiotic regimens [25]) and based on initial serum procalcitonin level (above or below the median). Fever at study inclusion was defined as a temperature of $>37.8^{\circ} \mathrm{C}[1]$.

All analyses were per protocol. Data analysis was done using Stata 12.1 (College Station, TX, USA). 


\section{Results}

Patients and microbiological findings

The trial included 726 patients (median age 69.6 years; 62\% men) treated per protocol, of whom 362 and 364 patients were randomised to the prednisone and placebo groups, respectively [1]. The baseline characteristics are shown in table 1. A microbiological diagnosis was made in 226 (36.6\%) of the 726 patients, including Streptococcus pneumoniae $(\mathrm{n}=106)$, other bacteria $(\mathrm{n}=59)$, influenza viruses $(\mathrm{n}=24)$ and respiratory viruses other than influenza $(n=51)$ (table 1$)$. The 30 -day mortality was $15(4.1 \%)$ out of 362 in the prednisone group, and $13(3.6 \%)$ out of 364 in the placebo group. Secondary ICU admission was recorded in two patients in the prednisone group (in none of whom a pathogen was documented), and 10 patients in the placebo group (of which two patients had pneumococcal pneumonia, one patient had influenza, and seven patients had no microbiological diagnosis made).

\section{TTCS in patients with pneumococcal pneumonia}

Pneumococcal pneumonia was diagnosed in 106 patients (41 patients by blood culture; 18 by sputum culture; one by bronchoalveolar lavage; and 46 by urine antigen testing), of whom 53 patients were randomised to prednisone and 53 to placebo. In unadjusted analysis, the median (interquartile range) TTCS was not different between the prednisone group and the placebo group (3.4 (1.5-8.5) days versus 3.6 (2.0-5.9) days; unadjusted hazard ratio 0.97 (0.65-1.43); table 2), with a significant result in the interaction analysis (unadjusted interaction $\mathrm{p}=0.04$; supplementary table $\mathrm{S} 1$ ). The overall distribution of PSI classes was not different in the prednisone and placebo groups $(\mathrm{p}=0.41$; table 3$)$, but more patients in the prednisone arm were classified to PSI class IV or V (29 (55\%) out of 53) than in the placebo arm (19 (36\%) out of 53). In addition, in the prednisone arm significantly more patients had heart failure at baseline than in the placebo group and they tended to be older and to have more cerebrovascular disease (table 3). After adjustment for these baseline factors, the interaction was no longer significant in patients with pneumococcal pneumonia, with TTCS now being shorter in the prednisone group compared with the placebo group (table 2; adjusted H 1.28 (0.85-1.94); adjusted interaction $\mathrm{p}=0.14$ ).

\section{Secondary outcomes in patients with pneumococcal pneumonia}

In pneumococcal pneumonia, we found evidence for a different prednisone response. The duration of intravenous antibiotics was not shorter with prednisone compared with placebo (adjusted interaction $\mathrm{p}=0.01$ ). There also were trends for effect modification in regard to length of hospital stay and total duration of antibiotic treatment (table 4) [1]. After adjusting for multiple testing, these different subgroup effects were no longer significant.

\section{TTCS and secondary outcomes in other microbiological subgroups}

The median TTCS in the microbiological subgroups is shown in table 2. A more rapid TTCS with prednisone compared with placebo was identified in patients with and those without a CAP pathogen identified, in patients with or without a bacterial pathogen identified, in patients with and without influenza virus, and in patients with and without a respiratory viral pathogen identified in the nasopharynx. Adjustment for baseline characteristics did not alter the estimates (supplementary table S1).

There were no significant differences regarding secondary outcomes compared to the entire study population (supplementary table S1). In patients with any CAP pathogen and in patients with a bacterial CAP pathogen identified, there was an increased ICU admission rate in the prednisone group compared with the placebo group (supplementary table S1). This difference was, however, attributable to the patients with pneumococcal pneumonia contained in these two subgroups, and was no longer apparent when the pneumococcal pneumonia patients were removed from the subgroups.

\section{TTCS and secondary outcomes according to antimicrobial regimen}

The most frequently administered antimicrobial regimens included combined therapy using a $\beta$-lactam and clarithromycin $(n=404)$, a $\beta$-lactam only $(n=199)$, and a variety of other antibiotics $(n=109)$. In 10 patients, no antibiotics were given based on low serum procalcitonin levels (table 2). A more rapid TTCS in the prednisone group than in the placebo group was identified in all antimicrobial subgroups (table 2).

Regarding secondary outcomes, the re-hospitalisation rate did not differ in the entire study population between the prednisone and the placebo group [1]. In contrast, there was a trend towards an increased rate of re-hospitalisations in the prednisone group compared with the placebo group in those patients who did not receive $\beta$-lactam/clarithromycin combination therapy and a trend towards increased re-hospitalisation in patients who received $\beta$-lactam monotherapy (supplementary table S1). Sensitivity analysis confirmed such a trend also in patients who never received a macrolide which became statistically significant after adjustment for baseline characteristics (supplementary table S1). The macrolide used in all cases was clarithromycin except for one patient who received azithromycin. 
TABLE 1 Baseline characteristics of participants (per protocol population)

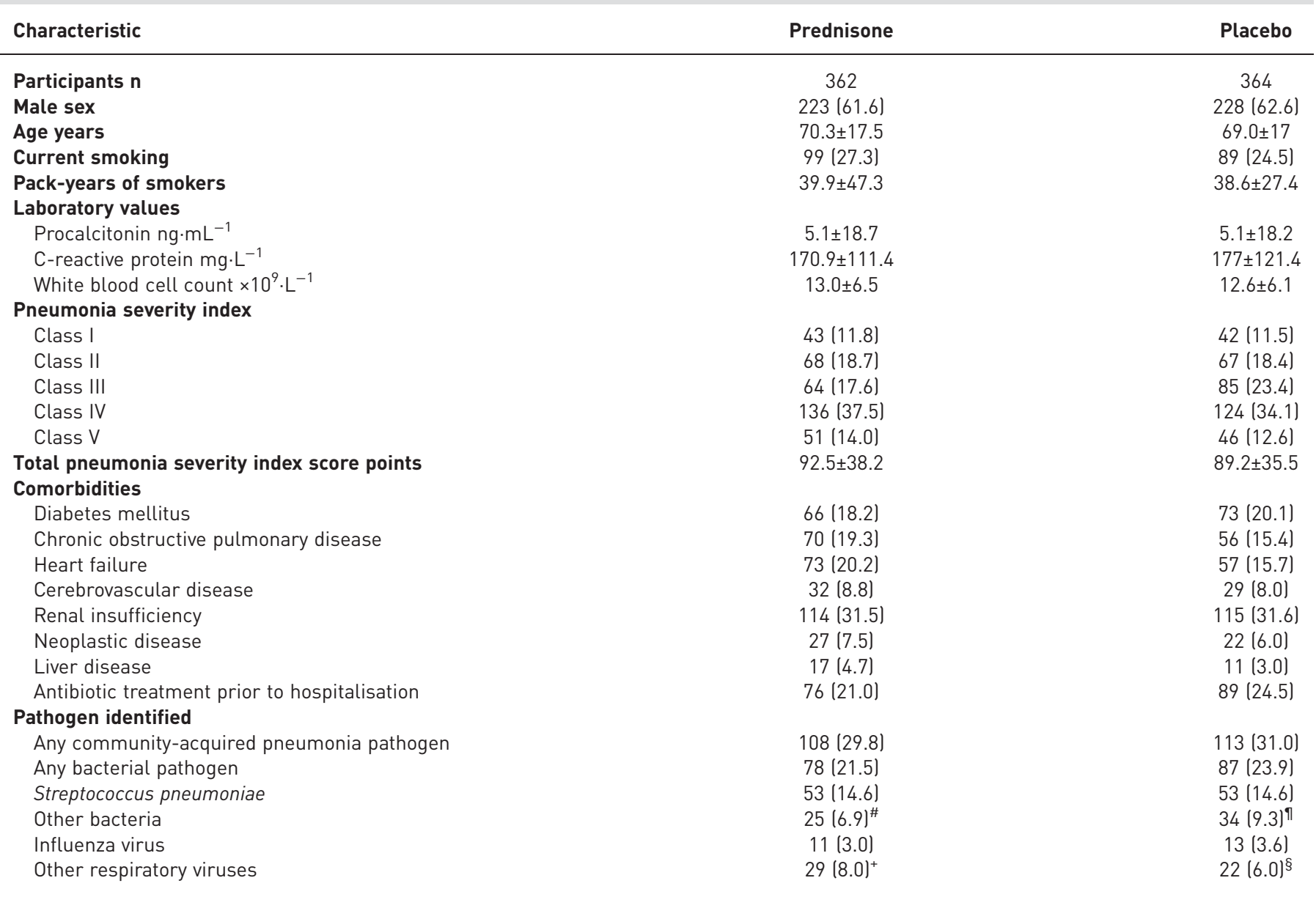

Data are presented as mean \pm SD or $\mathrm{n}(\%)$, unless otherwise stated. \#: includes three Escherichia coli (bacteraemia), five Pseudomonas spp. (one bacteraemia, two sputum culture, two bronchoalveolar lavage), one Staphylococcus aureus (bacteraemia), one Streptococcus agalactiae (bacteraemia), two Streptococcus dysgalactiae (bacteraemia), one Streptococcus milleri (bacteraemia), two Enterobacteriaceae (sputum culture), one gram-positive rod-shaped bacteria (sputum culture), two Haemophilus influenza (sputum culture), one Hafnia alvei (sputum culture), one Klebsiella sp. (sputum culture), two Legionella pneumophila (one urinary antigen and sputum culture, one urinary antigen), two Mycoplasma pneumoniae (one sputum culture, one nasopharyngeal PCR), one Serratia marcescens (sputum culture); ๆ: includes one Achromobacter xylosoxidans (bacteraemia), one combined infection of S. aureus (bacteraemia) and H. influenza (sputum culture), four E. coli (bacteraemia), one group C Streptococcus sp. (bacteraemia), one Proteus mirabilis (bacteraemia), two S. marcescens (one bacteraemia, one sputum culture), two S. aureus (one bacteraemia, one sputum culture), one S. dysgalactiae (bacteraemia), one Streptococcus malans (bacteraemia), one S. milleri (bacteraemia), one Streptococcus sanguinis (bacteraemia), one Streptococcus vestibularis (bacteraemia), one aerobic bacteria (sputum culture), one Citrobacter freundii (sputum culture), one combined infection of $H$. influenza and Klebsiella pneumoniae (sputum culture), one combined infection of $H$. influenza and S. marcescens (sputum culture), one combined infection of $L$. pneumophila (urinary antigen and sputum culture) with $H$. influenza and Enterobacter sp. (sputum culture), one combined infection of S. marcescens and Enterobacter sp. (sputum culture), one combined infection of $S$. aureus with Klebsiella oxytoca and Proteus vulgaris (sputum culture), one Enterobacter sp. (sputum culture), one gram-negative rod-shaped bacteria (sputum culture), three H. influenza (sputum culture), one K. pneumoniae (sputum culture), one Mycoplasma pneumoniae (sputum culture), one Stenotrophomonas maltophilia (sputum culture), one combined infection of K. pneumoniae and Pseudomonas aeruginosa (bronchoalveolar lavage), one gram-negative rod-shaped bacteria (bronchoalveolar lavage); ${ }^{+}$: includes five respiratory syncytial virus, one parainfluenza virus-4, six metapneumovirus, seven coxsackie virus, three rhinovirus, one combined rhinovirus and adenovirus, four coronavirus, one bocavirus, one adenovirus (all in nasopharyngeal swabs by PCR); ${ }^{\S}$ includes five respiratory syncytial virus, one combined respiratory syncytial virus and parainfluenza virus $1-3$, one parainfluenza virus $1-3$, one combined influenza $A$ and metapneumovirus, one metapneumovirus, five coxsackie virus, five rhinovirus, one adenovirus, one combined rhinovirus and adenovirus, one bocavirus (all in nasopharyngeal swabs by PCR).

TTCS according to initial procalcitonin level

We then investigated whether the effect of adjunct prednisone on TTCS is related to the initial procalcitonin level, i.e. above or below $0.5 \mu \mathrm{g} \cdot \mathrm{L}^{-1}$, the median initial procalcitonin level in the entire study population. A more rapid TTCS in the prednisone group compared with the placebo group was identified in both procalcitonin subgroups (table 2), with no evidence for interaction. Secondary outcomes were not different in the two procalcitonin subgroups, except for a trend towards a more pronounced effect of 
TABLE 2 Days to clinical stability according to microbiological diagnosis, antimicrobial treatment group, and initial procalcitonin level

\begin{tabular}{|c|c|c|c|c|c|c|c|c|}
\hline & Prednisone & Placebo & $\begin{array}{l}\text { Adjusted hazard ratio } \\
\text { (95\% confidence } \\
\text { interval }]\end{array}$ & & Prednisone & Placebo & $\begin{array}{l}\text { Adjusted hazard ratio } \\
\text { [95\% confidence } \\
\text { interval] }\end{array}$ & $\begin{array}{c}\text { Interaction } \\
\text { p-value }\end{array}$ \\
\hline \multicolumn{9}{|l|}{ Microbiological subgroup } \\
\hline $\begin{array}{l}\text { Any pathogen (prednisone } n=108 \text {; } \\
\text { placebo } n=113 \text { ) }\end{array}$ & $3.4(2.0-7.0)$ & $4.4(2.4-8.0)$ & $1.36(1.03-1.80)$ & $\begin{array}{l}\text { All others ( } \text { prednisone } \\
n=254 ; \text { placebo } n=251 \text { ) }\end{array}$ & $2.6(1.9-5.0)$ & $4.5(2.2-8.0)$ & $1.63(1.36-1.96)$ & 0.26 \\
\hline $\begin{array}{l}\text { Bacterial ( prednisone } n=78 \\
\text { placebo } n=87 \text { ) }\end{array}$ & $3(1.5-7.0)$ & $4(2.4-9.0)$ & $1.54(1.11-2.14)$ & $\begin{array}{l}\text { All others ( prednisone } \\
n=258 \text {; placebo } n=245 \text { ) }\end{array}$ & $3(2.0-5.0)$ & $4.5(2.3-7.5)$ & $1.46(1.22-1.75)$ & 1 \\
\hline $\begin{array}{l}\text { Pneumococcal (prednisone } n=53 \text {; } \\
\text { placebo } n=53 \text { ) }\end{array}$ & $3.4(1.5-8.5)$ & $3.6(2.0-5.9)$ & $1.28(0.85-1.94)$ & $\begin{array}{l}\text { All others ( } \text { prednisone } \\
n=250 ; \text { placebo } n=268 \text { ) }\end{array}$ & $3.0(2.0-5.3)$ & $5(2.5-8.3)$ & $1.60(1.33-1.91)$ & 0.14 \\
\hline $\begin{array}{l}\text { Respiratory virus ( } p r e d n i s o n e \\
n=40 ; \text { placebo } n=35 \text { ) }\end{array}$ & $4(3.0-6.6)$ & $4.4(2.4-7)$ & $1.21(0.74-1.98)$ & $\begin{array}{l}\text { All others (prednisone } \\
\mathrm{n}=174 ; \text { placebo } \mathrm{n}=183 \text { ) }\end{array}$ & $3.0(2.0-5.4)$ & $4.5(2.3-8.0)$ & $1.52(1.22-1.89)$ & 0.40 \\
\hline $\begin{array}{l}\text { Influenza virus ( } \text { prednisone } n=11 \text {; } \\
\text { placebo } n=13 \text { ) }\end{array}$ & $4.0(1.4-7.0)$ & $5.0(3.0-10.4)$ & $4.50(1.17-17.25)$ & $\begin{array}{l}\text { All others ( } \text { prednisone } \\
\mathrm{n}=203 \text {; placebo } \mathrm{n}=205 \text { ) }\end{array}$ & $3.0(2.0-5.5)$ & $4.4(2.3-7.5)$ & $1.45(1.18-1.77)$ & 0.91 \\
\hline \multicolumn{9}{|l|}{ Antimicrobial subgroup } \\
\hline $\begin{array}{l}\beta \text {-lactam plus macrolide } \\
\quad \text { (prednisone } n=205 \text {; placebo } n=199 \text { ) }\end{array}$ & $3.0(2.0-6.0)$ & $5(2.3-8.0)$ & $1.52(1.23-1.86)$ & $\begin{array}{l}\text { All others ( } \text { prednisone } \\
n=156 ; \text { placebo } n=162 \text { ) }\end{array}$ & $2.4(1.4-4.9)$ & $4(2.0-7.0)$ & $1.46(1.16-1.83)$ & 0.88 \\
\hline $\begin{array}{l}\beta \text {-lactam only (prednisone } n=103 \text {; } \\
\text { placebo } n=96 \text { ) }\end{array}$ & $2.0(1.3-4.4)$ & $3.0(2.0-6.0)$ & $1.28(0.96-1.71)$ & $\begin{array}{l}\text { All others ( } \text { prednisone } \\
\mathrm{n}=258 \text {; placebo } \mathrm{n}=265 \text { ) }\end{array}$ & $3.0(2.0-6.0)$ & $5.0(2.4-8.4)$ & $1.58(1.32-1.89)$ & 0.33 \\
\hline $\begin{array}{l}\text { All other antibiotics ( prednisone } \\
\mathrm{n}=47 \text {; placebo } \mathrm{n}=62 \text { ) }\end{array}$ & $3.0(1.4-6.0)$ & $5.0(3.0-9.0)$ & $1.78(1.18-2.69)$ & $\begin{array}{l}\text { All others ( } \text { prednisone } \\
n=314 ; \text { placebo } n=299 \text { ) }\end{array}$ & $3.0(2.0-5.4)$ & $4.3(2.0-7.6)$ & $1.42(1.20-1.67)$ & 0.44 \\
\hline $\begin{array}{l}\text { Sensitivity analysis: ever received } \\
\text { a macrolide (prednisone } n=225 \\
\text { placebo } n=234 \text { ) }\end{array}$ & $3.0(2.0-6.0)$ & $5.0(2.0-8.4)$ & $1.58(1.30-1.92)$ & $\begin{array}{l}\text { All others (prednisone } \\
n=136 ; \text { placebo } n=127 \text { ) }\end{array}$ & $2.0(1.4-4.5)$ & $3.4(2.0-6.0)$ & $1.31(1.02-1.68)$ & 0.98 \\
\hline \multicolumn{9}{|l|}{ Initial procalcitonin } \\
\hline $\begin{array}{l}\text { Above the median (prednisone } \\
n=141 ; \text { placebo } n=148 \text { ) }\end{array}$ & $2.6(1.9-5.4)$ & $4.5(2.5-8.7)$ & $1.75(1.37-2.25)$ & $\begin{array}{l}\text { Below the median } \\
\text { (prednisone } n=148 ; \\
\text { placebo } n=158 \text { ) }\end{array}$ & $2.4(1.5-4.5)$ & $4.0(2.0-7.0)$ & $1.44(1.14-1.82)$ & 0.51 \\
\hline \multicolumn{9}{|l|}{ Fever at inclusion } \\
\hline $\begin{array}{l}\text { Temperature } \leqslant 37.8^{\circ} \mathrm{C} \text { (prednisone } \\
n=226 ; \text { placebo } n=219 \text { ) }\end{array}$ & $2.5(1.5-5.4)$ & $4.0(2.0-7.6)$ & $1.27(1.05-1.54)$ & $\begin{array}{l}\text { Temperature }>37.8^{\circ} \mathrm{C} \\
\text { (prednisone } \mathrm{n}=137 \\
\text { placebo } \mathrm{n}=144 \text { ) }\end{array}$ & $3.0(2.0-5.5)$ & $5.0(3.0-8.4)$ & $1.47(1.15-1.86)$ & 0.57 \\
\hline
\end{tabular}


prednisone on reducing the duration of total and intravenous antibiotics with an initial procalcitonin level above the median (supplementary table S1).

\section{TTCS in afebrile participants}

Of the 726 trial participants, 281 were febrile and 445 were afebrile at inclusion, respectively (table 2). The effect of prednisone versus placebo on TTCS was similar in patients with fever at inclusion (median (interquartile range) TCCS, 3.0 (2.0-5.5) days versus 5.0 (3.0-8.4) days; HR 1.47 (95\% CI 1.15-1.86)), and patients without fever (TTCS 2.5 (1.5-5.4) days versus 4.0 (2.0-7.6) days; HR 1.27 (95\% CI 1.05-1.54); adjusted p=0.57).

\section{Discussion}

Here we report three major findings. Given the limited size of certain subgroups and multiple comparisons, these findings should be regarded as exploratory. First, adjunct prednisone led to a reduced TTCS in all microbiological, antibiotic, procalcitonin and afebrile patient subgroups, consistent with the beneficial corticosteroid effect we previously reported in our large randomised, placebo-controlled trial in patients hospitalised with CAP [1]. Second, we observed no detrimental effects of prednisone in patients with viral or influenza pneumonia. Third, the prednisone effect was different in certain subgroups, i.e. prednisone was associated with longer duration of antibiotics in pneumococcal pneumonia and with increased rehospitalisation rate in patients who did not receive macrolide treatment.

In patients with pneumococcal pneumonia, the prednisone benefit on TTCS was somewhat smaller than in the other subgroups and prednisone was associated with increased duration of intravenous antibiotics and trends towards longer antibiotic treatment and longer hospital stay. However, we believe that these potentially adverse prednisone effects need to be interpreted cautiously: First, prednisone in pneumococcal CAP was not associated with an increased risk of late treatment failure, empyema or recurrent pneumonia. Second, an adverse prednisone effect would be unexpected given the corticosteroid benefit in patients with pneumococcal meningitis in Western countries $[8,26]$, and given accumulating data that corticosteroids are potentially more beneficial in severe CAP $[2,7,27]$. Results from two ongoing trials in severe CAP, the ADRENAL (Adjunctive Corticosteroid Treatment in Critically Ill Patients With Septic Shock) and the ESCAPe (Extended Steroid in CAP(e)) trials (ClinicalTrials.gov NCT01448109 and NCT01283009), will hopefully help resolve this important issue.

Another randomised study including 113 patients with pneumococcal pneumonia did not document such a concern: WAGNER et al. [28] in 1956 described a beneficial effect of adjunct corticosteroids on the course of pneumococcal pneumonia. One patient died in each study arm (penicillin G plus hydrocortisone for 5 days versus penicillin $\mathrm{G}$ alone), there were no cases of empyema in either arm, and subjective improvement and defervescence were more rapid with hydrocortisone. In a more recent double-blind trial by SNIJDERS et al. [5], however, randomisation to prednisone in the subgroup of patients with pneumococcal pneumonia was associated with a lower clinical cure rate at day 30 (prednisone 20 of 42 patients versus placebo 28 of 36 patients; $\mathrm{p}=0.01$ ) and more late failures (prednisone 11 of 42 patients versus placebo 2 of 36 patients; $\mathrm{p}=0.02$ ). In three other recent studies of corticosteroids in CAP, patients with pneumococcal pneumonia were not analysed separately $[3,4,6]$.

While we cannot exclude residual and unmeasured confounding in this subgroup analysis, one might speculate why the corticosteroid benefit seen in the other microbiological subgroups might not equally extend to pneumococcal pneumonia. Outcome of pneumococcal pneumonia depends on several factors including prior viral infection, pneumococcal serotype, inoculum size and host response [29, 30]. In mice, lethal pneumococcal pneumonia correlated with progressive intra-alveolar increases in bacteria and neutrophils, while mice who recovered had low intra-alveolar bacterial and neutrophil counts [31]. Corticosteroids in vivo may [32] or may not reduce neutrophilic inflammation, however, and are well-known to induce a dose-dependent neutrophilia, which in vitro has been related to prolonged neutrophil survival by inhibiting their apoptosis $[33,34]$. In asthma, chronic obstructive pulmonary disease and allergic rhinitis, steroids (when given by inhalation, orally or nasally) do not reduce neutrophil levels intranasally or in induced sputum $[35,36]$. Moreover, in Dutch patients with CAP due to atypical or unknown organisms, most serum inflammatory cytokines decreased more rapidly after corticosteroids than after placebo [37]. In contrast, in pneumococcal pneumonia, the decreases of serum cytokine concentrations over time were no different in the corticosteroid and placebo groups [37]. This suggests that recovery from pneumococcal pneumonia may be affected by corticosteroids in a manner different from atypical CAP organisms.

Adjunct prednisone was also beneficial in patients in whom influenza virus and other respiratory viruses were recovered. This is reassuring, given prior concerns that corticosteroids could be harmful in patients with viral pneumonia. In a mouse model [32], in retrospective observational studies [13, 14] and in a meta-analysis [15], early use of corticosteroids in influenza virus infection was associated with increased bacterial superinfection, development of severe illness and mortality. Furthermore, corticosteroids were 
TABLE 3 Baseline characteristics in patients with and without pneumococcal pneumonia

\begin{tabular}{|c|c|c|c|c|c|c|}
\hline Characteristic & \multicolumn{3}{|c|}{ Pneumococcal pneumonia } & \multicolumn{3}{|c|}{ All others } \\
\hline Participants n & 53 & 53 & & 250 & 268 & \\
\hline Age years & $70 \pm 17$ & $64 \pm 17$ & 0.07 & $71 \pm 17$ & $70 \pm 17$ & 0.51 \\
\hline Current smoking & $15(28)$ & $13(25)$ & 0.66 & 73 (29) & $70(26)$ & 0.43 \\
\hline Pack-years of smokers & $23 \pm 31$ & $17 \pm 24$ & 0.29 & $23 \pm 39$ & $22 \pm 28$ & 0.65 \\
\hline C-reactive protein $\mathrm{mg} \cdot \mathrm{L}^{-1}$ & $238 \pm 133$ & $241 \pm 132$ & 0.90 & $165 \pm 103$ & $174 \pm 117$ & 0.37 \\
\hline White blood cell count $\times 10^{9} \cdot \mathrm{L}^{-1}$ & $14.9 \pm 7.5$ & $13.3 \pm 6.1$ & 0.22 & $12.8 \pm 6.3$ & $12.7 \pm 6.2$ & 0.83 \\
\hline Pneumonia severity index & & & 0.41 & & & 0.78 \\
\hline Class I & $6(11)$ & $8(15)$ & & $27(11)$ & $31(12)$ & \\
\hline Class II & $12(23)$ & $16(30)$ & & $43(17)$ & $44(16)$ & \\
\hline Class III & $6(11)$ & $10(19)$ & & $48(19)$ & $63(24)$ & \\
\hline Diabetes mellitus & $8(15)$ & $7(13)$ & 0.78 & $52(21)$ & $58(22)$ & 0.80 \\
\hline Chronic obstructive pulmonary disease & $13(25)$ & $8(15)$ & 0.22 & $49(20)$ & $40(15)$ & 0.16 \\
\hline Heart failure & $12(23)$ & $4(8)$ & 0.03 & $43(17)$ & $45(17)$ & 0.92 \\
\hline Cerebrovascular disease & $3(6)$ & 0 & 0.08 & $27(11)$ & $24(9)$ & 0.49 \\
\hline Renal insufficiency & $19(36)$ & $16(30)$ & 0.54 & $81(32)$ & $83(31)$ & 0.75 \\
\hline Neoplastic disease & $4(8)$ & $6(11)$ & 0.51 & $19(8)$ & $14(5)$ & 0.27 \\
\hline Antibiotic treatment prior to hospitalisation & $7(13)$ & $9(17)$ & 0.59 & $51(20)$ & $70(26)$ & 0.12 \\
\hline
\end{tabular}

Data are presented as mean \pm SD or $\mathrm{n}(\%)$, unless otherwise stated.

associated with prolonged plasma viraemia in patients with SARS-associated coronavirus infection [10], prolonged respiratory viral shedding in patients hospitalised with influenza [11], increased risk of death in acute respiratory distress syndrome after severe H1N1 influenza [12] and with no beneficial effect in mechanically ventilated infants with severe respiratory syncytial virus infection [9].

In our randomised trial, the prednisone benefit was valid across the most commonly administered antibiotic groups. An increased rehospitalization rate was observed in patients who did not receive a macrolide. These findings support previous data on a potentially beneficial, immunomodulating effect of macrolides in some [25, 38] but not other [39] CAP studies, but need to be interpreted with caution because antimicrobial treatment in our trial was not randomly allocated. Therefore, this could be a chance finding and needs to be confirmed.

We previously reported in the entire study population that adjunct prednisone led to more rapid TTCS independently of initial median C-reactive protein level or blood culture positivity [1]. We now show that the prednisone benefit was also independent of the initial procalcitonin level. High levels of this biomarker may indicate more severe systemic infection, and low levels suggest that antibiotics may not be required in CAP [21].

Our study has limitations. We tested several subgroups which increases the risk for false-positive results; future studies are needed to validate our findings. Despite deriving from the largest randomised trial of corticosteroids in CAP to date, the number of patients in certain microbiological subgroups was small. This limited our ability to detect differences between the prednisone and placebo arms; therefore, our results should be interpreted with appropriate caution. In part, some subgroups were small because microbiological investigations were not systemically done but were at the discretion of the attending physician. This reflects the "real life" setting of the trial. Nonetheless, multiplex viral PCR testing on nasopharyngeal swabs was systematically performed in $67 \%$ of participants, to address concerns that steroids might be harmful in viral pneumonia. Despite randomisation, there were imbalances, particularly in the pneumococcal subgroup, with respect to severity of disease and co-morbidities between the prednisone and placebo arm that we aimed to account for by adjusting for these baseline characteristics. Finally, the baseline PSI score (mean, 90 points), the 30-day mortality rate (approximately $4 \%$ ) in our population and the prednisone dose and duration employed in our trial (50 $\mathrm{mg}$ for 7 days) should be considered when extrapolating our results to other populations. 
TABLE 4 Secondary outcomes in patients with pneumococcal pneumonia

\begin{tabular}{|c|c|c|c|c|c|c|c|}
\hline \multirow[t]{2}{*}{ Secondary endpoints } & \multicolumn{2}{|c|}{ Pneumococcal pneumonia } & \multirow[b]{2}{*}{$\begin{array}{c}\text { HR, OR or } \\
\text { difference }(95 \% \mathrm{Cl})\end{array}$} & \multicolumn{2}{|c|}{ All others } & \multirow[b]{2}{*}{$\begin{array}{c}\text { HR, OR or } \\
\text { difference }(95 \% \mathrm{CI})\end{array}$} & \multirow{2}{*}{$\begin{array}{l}\text { Interaction } \\
\text { p-value }\end{array}$} \\
\hline & $\begin{array}{l}\text { Prednisone } \\
\quad(n=53)\end{array}$ & $\begin{array}{l}\text { Placebo } \\
\text { (n=53) }\end{array}$ & & $\begin{array}{l}\text { Prednisone } \\
(n=250)\end{array}$ & $\begin{array}{l}\text { Placebo } \\
\text { (n=268) }\end{array}$ & & \\
\hline Time to effective hospital discharge days & $8.8(6.0)$ & $7.5(5.5)$ & $\begin{array}{c}\text { Unadjusted difference: } \\
1.26(-0.95-3.48) \text { days; adjusted } \\
\text { difference: } 0.34 \text { (-1.61-2.30) days }\end{array}$ & $8.0(6.0)$ & $9.0(6.1)$ & $\begin{array}{c}\text { Unadjusted difference: } \\
-1.02(-2.07-0.03) \text { days; adjusted } \\
\text { difference: }-1.24(-2.22--0.26) \text { days }\end{array}$ & $\begin{array}{l}\text { Unadjusted: } 0.08 ; \\
\text { adjusted: } 0.16\end{array}$ \\
\hline Death from any cause $n$ & $1(2)$ & $3(6)$ & $\begin{array}{l}\text { Unadjusted OR: } 0.32 \text { (0.03-3.18); } \\
\text { adjusted OR: } 0.09 \text { (0.005-1.48) }\end{array}$ & $10(4.0)$ & $10(3.7)$ & $\begin{array}{l}\text { Unadjusted OR: } 1.08 \text { (0.44-2.63); } \\
\text { adjusted OR: } 0.79 \text { (0.30-2.12) }\end{array}$ & $\begin{array}{l}\text { Unadjusted: } 0.34 ; \\
\text { adjusted: } 0.28\end{array}$ \\
\hline Re-admission to hospital $\mathrm{n}$ & 5 (9) & $2(4)$ & $\begin{array}{l}\text { Unadjusted OR: } 2.66 \text { (0.49-14.35); } \\
\text { adjusted OR: } 2.45 \text { (0.43-13.94) }\end{array}$ & $23(9.2)$ & $22(8.2)$ & $\begin{array}{l}\text { Unadjusted OR: } 1.13(0.61-2.09) ; \\
\text { adjusted OR: } 1.07(0.57-1.99)\end{array}$ & $\begin{array}{l}\text { Unadjusted: } 0.35 ; \\
\text { adjusted: } 0.51\end{array}$ \\
\hline CAP complications $n$ & $2(4)$ & $3(6)$ & $\begin{array}{l}\text { Unadjusted OR: } 0.65 \text { (0.10-4.08); } \\
\text { adjusted OR: } 0.46(0.06-3.49)\end{array}$ & $6(2.4)$ & $14(5.2)$ & $\begin{array}{l}\text { Unadjusted OR: } 0.45(0.17-1.18) ; \\
\text { adjusted OR: } 0.39(0.14-1.06)\end{array}$ & $\begin{array}{l}\text { Unadjusted: } 0.72 ; \\
\text { adjusted: } 0.76\end{array}$ \\
\hline Duration of total antibiotic treatment days & $11.4(8.2)$ & $10.2(4.6)$ & $\begin{array}{c}\text { Unadjusted difference: } \\
1.20(-1.42-3.82) \text { days; adjusted } \\
\text { difference: } 1.13(-1.37-3.62) \text { days }\end{array}$ & $9.5(4.6)$ & $10.1(4.9)$ & $\begin{array}{l}\text { Unadjusted difference: } \\
-0.62(-1.46-0.22) \text { days; } \\
\text { adjusted difference } \\
-0.70(-1.53-0.13) \text { days }\end{array}$ & $\begin{array}{l}\text { Unadjusted: } 0.10 ; \\
\text { adjusted: } 0.13\end{array}$ \\
\hline $\begin{array}{l}\text { Duration of intravenous antibiotic } \\
\text { treatment days }\end{array}$ & $7.3(8.3)$ & $5.6(3.9)$ & $\begin{array}{c}\text { Unadjusted difference: } \\
1.74 \text { (-0.81-4.29) days; adjusted } \\
\text { difference: } 1.62 \text { (-0.84-4.08) days }\end{array}$ & $5.2(4.0)$ & $6.4(5.0)$ & $\begin{array}{c}\text { Unadjusted difference: } \\
-1.14(-1.95--0.34) \text { days; adjusted } \\
\text { difference: }-1.25(-2.09--0.41) \text { days }\end{array}$ & $\begin{array}{l}\text { Unadjusted: } 0.01 ; \\
\text { adjusted: } 0.01\end{array}$ \\
\hline
\end{tabular}

Data are presented as median (interquartile range) and $\mathrm{n}(\%)$, unless otherwise stated. CAP: community-acquired pneumonia; ICU: intensive care unit. 
An important question regards which aspects of time to clinical stability are affected by prednisone. Because clinical stability was defined as all instability criteria to have normalised, this question can only be answered indirectly based on our trial (refer to table S3 in the supplementary material of [1] for the instability criteria present in patients randomised to prednisone and placebo at baseline). Importantly, we show that prednisone was associated with more rapid TTCS in patients with and without fever at baseline, suggesting that the prednisone effect in CAP derives from physiological benefits in addition to simply an antipyretic effect.

\section{Acknowledgements}

The authors thank Daniel Genné for his critical review of the manuscript. Members of the Steroids in Pneumonia (STEP) Study Group include: Claudine Angela Blum, Nicole Nigro, Matthias Briel, Philipp Schuetz, Elke Ullmer, Isabelle Suter-Widmer, Bettina Winzeler, Roland Bingisser, Hanno Elsaesser, Daniel Drozdov, Birsen Arici, Sandrine Andrea Urwyler, Julie Refardt, Philip E. Tarr, Sebastian Wirz, Robert Thomann, Christine Baumgartner, Hervé Duplain, Dieter Burki, Werner Zimmerli, Nicolas Rodondi, Beat Mueller, Mirjam Christ-Crain.

\section{References}

1 Blum CA, Nigro N, Briel M, et al. Adjunct prednisone therapy for patients with community-acquired pneumonia: a multicentre, double-blind, randomised, placebo-controlled trial. Lancet 2015; 385: 1511-1518.

2 Siemieniuk RAC, Meade MO, Alonso-Coello P, et al. Corticosteroid therapy for patients hospitalized with community-acquired pneumonia: asystematic review and meta-analysis. Ann Intern Med 2015; 163: 519-528.

3 Confalonieri M, Urbino R, Potena A, et al. Hydrocortisone infusion for severe community-acquired pneumonia: a preliminary randomized study. Am J Respir Crit Care Med 2005; 171: 242-248.

4 Garcia-Vidal C, Calbo E, Pascual V, et al. Effects of systemic steroids in patients with severe community-acquired pneumonia. Eur Respir J 2007; 30: 951-956.

5 Snijders D, Daniels JMA, de Graaff CS, et al. Efficacy of corticosteroids in community-acquired pneumonia: a randomized double-blinded clinical trial. Am J Respir Crit Care Med 2010; 181: 975-982.

6 Meijvis SCA, Hardeman H, Remmelts HH, et al. Dexamethasone and length of hospital stay in patients with community-acquired pneumonia: a randomised, double-blind, placebo-controlled trial. Lancet 2011; 377: 2023-2030.

7 Torres A, Sibila O, Ferrer M, et al. Effect of corticosteroids on treatment failure among hospitalized patients with severe community-acquired pneumonia and high inflammatory response: a randomized clinical trial. JAMA 2015; 313: 677-686.

8 de Gans J, van de Beek D, European Dexamethasone in Adulthood Bacterial Meningitis Study Investigators. Dexamethasone in adults with bacterial meningitis. N Engl J Med 2002; 347: 1549-1556.

9 van Woensel JBM, van Aalderen WMC, de Weerd W, et al. Dexamethasone for treatment of patients mechanically ventilated for lower respiratory tract infection caused by respiratory syncytial virus. Thorax 2003; 58: 383-387.

10 Lee N, Allen Chan KC, Hui DS, et al. Effects of early corticosteroid treatment on plasma SARS-associated Coronavirus RNA concentrations in adult patients. J Clin Virol 2004; 31: 304-309.

11 Lee N, Chan PKS, Hui DSC, et al. Viral loads and duration of viral shedding in adult patients hospitalized with influenza. J Infect Dis 2009; 200: 492-500.

12 Brun-Buisson C, Richard J-CM, Mercat A, et al. Early corticosteroids in severe influenza A/H1N1 pneumonia and acute respiratory distress syndrome. Am J Respir Crit Care Med 2011; 183: 1200-1206.

13 Han $\mathrm{K}, \mathrm{Ma} \mathrm{H}$, An X, et al. Early use of glucocorticoids was a risk factor for critical disease and death from pH1N1 infection. Clin Infect Dis 2011; 53: 326-333.

14 Lee N, Leo Y-S, Cao B, et al. Neuraminidase inhibitors, superinfection and corticosteroids affect survival of influenza patients. Eur Respir J 2015; 45: 1642-1652.

15 Zhang Y, Sun W, Svendsen ER, et al. Do corticosteroids reduce the mortality of influenza A (H1N1) infection? A meta-analysis. Crit Care 2015; 19: 46.

16 Cillóniz C, Ewig S, Polverino E, et al. Microbial aetiology of community-acquired pneumonia and its relation to severity. Thorax 2011; 66: 340-346.

17 Musher DM, Roig IL, Cazares G, et al. Can an etiologic agent be identified in adults who are hospitalized for community-acquired pneumonia: results of a one-year study. J Infect 2013; 67: 11-18.

18 Jain S, Self WH, Wunderink RG, et al. Community-acquired pneumonia requiring hospitalization among U.S. adults. N Engl J Med 2015; 373: 415-427.

19 Christ-Crain M, Jaccard-Stolz D, Bingisser R, et al. Effect of procalcitonin-guided treatment on antibiotic use and outcome in lower respiratory tract infections: cluster-randomised, single-blinded intervention trial. Lancet 2004; 363: 600-607.

20 Christ-Crain M, Stolz D, Bingisser R, et al. Procalcitonin guidance of antibiotic therapy in community-acquired pneumonia: a randomized trial. Am J Respir Crit Care Med 2006; 174: 84-93.

21 Schuetz P, Christ-Crain M, Thomann R, et al. Effect of procalcitonin-based guidelines $v s$ standard guidelines on antibiotic use in lower respiratory tract infections: the ProHOSP randomized controlled trial. JAMA 2009; 302: 1059-1066.

22 Ricard J-D, Messika J. Corticosteroid therapy for pneumonia. Lancet 2015; 386 : 954.

23 Johnstone J, Majumdar SR, Fox JD, et al. Viral infection in adults hospitalized with community-acquired pneumonia: prevalence, pathogens, and presentation. Chest 2008; 134: 1141-1148.

24 Johansson N, Kalin M, Tiveljung-Lindell A, et al. Etiology of community-acquired pneumonia: increased microbiological yield with new diagnostic methods. Clin Infect Dis 2010; 50: 202-209.

25 Garin N, Genné D, Carballo S, et al. $\beta$-Lactam monotherapy vs $\beta$-lactam-macrolide combination treatment in moderately severe community-acquired pneumonia: a randomized noninferiority trial. JAMA Intern Med 2014; 174: 1894-1901.

26 Brouwer MC, McIntyre P, Prasad K, et al. Corticosteroids for acute bacterial meningitis. Cochrane Database Syst Rev 2013; 6: CD004405. 
27 Nie W, Zhang Y, Cheng J, et al. Corticosteroids in the treatment of community-acquired pneumonia in adults: a meta-analysis. PLoS one 2012; 7: e47926.

28 Wagner HN, Bennett IL, Lasagna L, et al. The effect of hydrocortisone upon the course of pneumococcal pneumonia treated with penicillin. Bull Johns Hopkins Hosp 1956; 98: 197-215.

29 Johnston RB. Pathogenesis of pneumococcal pneumonia. Rev Infect Dis 1991; 13: Suppl 6, S509-S517.

30 van der Poll T, Opal SM. Pathogenesis, treatment, and prevention of pneumococcal pneumonia. Lancet 2009; 374: 1543-1556.

31 Dallaire F, Ouellet N, Bergeron Y, et al. Microbiological and inflammatory factors associated with the development of pneumococcal pneumonia. J Infect Dis 2001; 184: 292-300.

32 Ghoneim HE, McCullers JA. Adjunctive corticosteroid therapy improves lung immunopathology and survival during severe secondary pneumococcal pneumonia in mice. J Infect Dis 2014; 209: 1459-1468.

33 Liles WC, Dale DC, Klebanoff SJ. Glucocorticoids inhibit apoptosis of human neutrophils. Blood 1995; 86: 3181-3188.

34 Cox G. Glucocorticoid treatment inhibits apoptosis in human neutrophils. Separation of survival and activation outcomes. J Immunol 1995; 154: 4719-4725.

35 Keatings VM, Jatakanon A, Worsdell YM, et al. Effects of inhaled and oral glucocorticoids on inflammatory indices in asthma and COPD. Am J Respir Crit Care Med 1997; 155: 542-548.

36 Benson M, Strannegård IL, Strannegård O, et al. Topical steroid treatment of allergic rhinitis decreases nasal fluid TH2 cytokines, eosinophils, eosinophil cationic protein, and IgE but has no significant effect on IFN- $\gamma$, IL- $1 \beta$, TNF- $\alpha$, or neutrophils. J Allergy Clin Immunol 2000; 106: 307-312.

37 Remmelts HHF, Meijvis SCA, Biesma DH, et al. Dexamethasone downregulates the systemic cytokine response in patients with community-acquired pneumonia. Clin Vaccine Immunol 2012; 19: 1532-1538.

38 Emmet O'Brien M, Restrepo MI, et al. Update on the combination effect of macrolide antibiotics in community-acquired pneumonia. Respir Investig 2015; 53: 201-209.

39 Postma DF, van Werkhoven $\mathrm{CH}$, van Elden LJR, et al. Antibiotic treatment strategies for community-acquired pneumonia in adults. $N$ Engl J Med 2015; 372: 1312-1323. 